\title{
The Effects of the Naval Profession on the Seafarers' Mental Health
}

\author{
Dimitrios Christodoulou \\ Dept. of Industrial Design and \\ Production Engineering University \\ of West Attica \\ Athens, Greece
}

\author{
Nikitas Nikitakos \\ Dpt. of Shipping Trade \& \\ Transport and Dpt. Industrial \\ Design \& Production Engineering \\ University of Aegean, Greece
}

\author{
Dimitrios Papachristos \\ Dept. of Industrial Design and \\ Production Engineering University \\ of West Attica \\ Athens, Greece
}

\begin{abstract}
Shipping constitutes a unique workplace where workers (seafarers) are confronted with many different stress / pressure factors. The naval profession is characterized by many as a very peculiar profession however, the seafarers work on board is not particularly difficult or heavy, at least when compared to other shore-based operations. However, in general terms, the peculiar nature of this profession is mainly due to the more general conditions under which the seafarer's work is carried out on board.
\end{abstract}

The workplace and the conditions prevailing in it play a key role in the lives of most workers, since a significant part of the time of life is spent there. The ship is a peculiar workplace that shows a number of adversities, which we rarely encounter in other professions. At the same time, working and living on board and interacting with the outside environment poses risks that the crew needs to learn to prevent, locate and deal with.

The purpose of this research is to study the effects of the naval profession on the psychosomatic condition of seafarers, identify possible causes that cause specific symptoms, and possible ways to address or minimize their impact on the working navy. Also, the role of maritime education and training in this subject will be examined.

\section{Keywords}

Working space, peculiar space, adversities, mental health, physical health, occupational stress, marine education and training.

\section{INTRODUCTION}

Shipping is a unique workplace where workers (seafarers) are faced with many different stressful factors. The naval profession is characterized by many as a very peculiar profession, although work on board is not particularly difficult or strenuous, when compared to land-based work. However, in general terms, the peculiarity of this profession is mainly due to the more general conditions under which the naval work is carried out on board. (K. Tripolitis 2007)

Some of the challenges - difficulties to be faced are the demanding programs, long hours of work, long periods away from family and friends, lack of support from companies, poor working conditions, indistinctive roles and poor social contacts due to multicultural colleagues.

According to the World Health Organization, "mental health" is defined as "a state of well-being, in which each individual realizes their potential, can manage the stress of everyday life, work efficiently and fruitfully and has the potential to contribute to their community". In short, to be mentally healthy, you must be physically, mentally and socially healthy. (Mental Health of Seafarers \& Disorders 2016)

Interest and concern about the psychosocial effects of work are constantly increasing. Moreover, raising awareness that the psychosocial aspects of life inside and outside the work environment can contribute to safety, performance, morale and attention at work.

A clear and often used definition of stress states that stress is caused through the processes of interaction between individuals and their environment. According to the above, when one feels that their personal abilities and powers are insufficient to meet the demands in their environment, they begin to experience intense stress. (VARVOGLI 2006) Occupational stress as a psychosocial risk is part of the new emerging risks that now appear to be a problem facing the complex European and Greek landscape of working relations and working conditions. (E. Thassias n.d.)

\section{IMPORTANCE OF RESEARCH}

Corresponding research in the field of Greek shipping has not been published so far. There are companies that carry out their own investigations, which concern their own staff and the data is not shared.

Partial efforts have been made in the context of diplomatic work at an undergraduate level, the conclusions of which have not been made public.

Internationally, similar surveys have been conducted in countries with an increased proportion of shipping workers [Philippines (Manalo, et al., 2015), Egypt (Essam El Sayed Ahmed Badawi n.d.)]

The International Committee of Seafarers' Welfare, recognizes the important role that lifestyle plays in health (mental and physical), promotes "MENTAL CARE" as one of the issues of the Seafarers' Health Information Program (Welfare nd)

In February 2006, the International Maritime Labor Conference (ILO) adopted the Maritime Labor Convention (MLC, 2006). This Convention lays down minimum requirements for the health, safety and well-being of seafarers, also described as the fourth pillar of maritime legislation, complementing the current legislation of STCW, SOLAS and MARPOL, which suggests that this convention is very much complex and extremely broad.

In addition, in 2012, the texts of Decisions Nos. STW / CONF2 / 33 and STCW / CONF2 / 34 of the Diplomatic Conference of the International Maritime Organization (IMO) - concerning the International Convention on Standards of Training, Certification and Watchkeeping for 1978 as amended (Standardson Training, Certification and 
WatchkeepingtheSeafarers 1978 asamended "- STCW).

\section{RESEARCH PREREQUISITES AND LIMITATIONS}

The survey (the) was completed by engineers (chiefs and masters), captains and first mates who attend courses at KESEN (Merchant Marine Training Center), in order to upgrade their diplomas. The sample is made up of Greek seamen. The questionnaire was filled out by seafarers while they were on shore and attending classes at KESEN.

The seafarers attend classes at KESEN for 21 days to upgrade their diploma to A' class Engineers and Captains and also 45 to 135 days to upgrade their diploma to B' class Engineers and First Mate. So, within these timeframes the questionnaires had to be distributed and registered, provided that there were no duplicate entries.

\section{PURPOSE AND OBJECTIVES OF RESEARCH}

This research in principle is to explore the factors that tend to enhance the stress of seafarers in their work and examine possible ways of improvement.

The performance of seafarers on board is of the utmost importance for the operation and successful outcome of the ship's mission.

There is no doubt that the world fleet is growing and instead of new candidates being hired, more duties are placed upon the existing crew.

Stress, on a case by case basis, can greatly reduce the efficiency and ability to manage emergencies.

Research questions are:

- Does maritime education and training help Greek seafarers to address stressful (stressful / pressing) situations at their workplace?

- Do the particularities and requirements of the nautical profession affect the Greek Navy's psychosis?

- Does the Greek Navy's personality play a role in managing situations in the workplace?

The factors contributing to anxiety, in summary, are:

- Incomplete knowledge

- Lack of training

- The absence of seminars and simulation lessons in real-world navigation conditions

- Increased hours of work combined with debilitating rate of work

- Personality of employees

Based on the above questions and the statistical processing of their data, it appears that all respondents answered that extra maritime education and training would be very useful. There is a correlation between the particular circumstances of the nautical profession and the mental state of the worker. It has been noticed that when the work load is overwhelming, people, especially those who are responsible, feel pressure beyond their limits. Finally, regarding health and safety necessary measures are taken. However, the average respondent claimed that recreational facilities were insufficient.

\section{THEORETICAL CONTEXT}

When a person faces a test and feels that some aspect of his or her existence is in danger, he feels anxious. Anxiety can be an element of the character of every person or occur occasionally. It is experienced in varying degrees and intensity by every person. If we compare stress with anxiety, we can examine the process as follows: the stressful stimulus stimulates the stress process and thus the individual experiences anxiety.

The word stress does not represent for everyone the same phenomenon, as the term is often generalized or oversimplified. All living organisms maintain a state of dynamic balance, caused by stimuli originating either from the organism or from the environment. The term comes from the English word "stress", which has its roots in the Latin words "strictus" and "stringere" (tight / passive share meaning "I'm tightening, I'm doing something more tightly").

As has been proven after surveys, most people feel pressure at their workplace. Work-related stress has to do with the detrimental physical and emotional responses that arise when the demands of the job do not match the employee's abilities or needs.

It is a general assumption that work-related stress is due to the influence of working conditions, although there is disagreement about what is more important for its challenge: the characteristics of the individual or the working conditions.

Well-being is defined as "a lasting and energetic process in which each person understands and learns that there are choices that can lead him to a longer-lasting and more quality life, towards a more general" well-being. "

We understand that seafarers, especially those working in the engine room of the ship, where the space is limited and working conditions quite difficult, are also facing such problems.

\section{RESEARCH METHOD AND SAMPLING}

According to the census made in 2014, the number of seafarers working on Greek and Greek ships was 22,925, of which 12,663 were of Greek nationality. (Inventory of merchant ships and crew results of 20 September 2014 n.d.).

A quantitative survey was conducted in the form of a questionnaire. A total of 900 questionnaires were gathered by seafarers of Greek nationality with the following data: 12,663 Greek seafarers (sample 7,10\%) (35,1\% masters - 62,2\% engineers) $(5,1 \%$ Women - 94,2\% Men)

\section{RESEARCH TOOLS}

Standard questionnaire with open-ended questions and 5-level questions. Open-ended questions are those that leave the respondent full freedom to express his / her preferences, thoughts and feelings by organizing his / her answer as he / she means, while closed-ended questions have predetermined answers. In the present study, a 5-scale scale was used where, according to the question group, 1 means none at all, 5 too much.

The questionnaire was based on samples from groups that conducted similar research abroad (J.Rengamani 2012), some questions - which emerged after discussion with active seafarers - were then added and then checked by a distinguished psychologist.

Questions, in addition to purely demographic, aim to "clarify" 
and identify the causes of stress and anxiety as reliably as possible.

\section{CREDIBILITY AND VALIDITY}

The reliability of the results was tested through the SPSS program and, in particular, the Alpha Crombach index Statistical packet like SPSS has changed the way of statistical surveys are approached. Its users can:

- Make transformations of the variables they use

- $\quad$ Create graphs of distributions and

- Select the corresponding statistical analysis packet that contains the specific program

"Alpha Crombach" index, ie Reliability factor, is one of the most popular tools for reliability of results in statistics is Alpha Crombach. This index determines the internal stability or the "average" correlation of variables as a research tool for calculating reliability. When the researcher has a variable or is created by queries that ultimately yield stable results, then this variable is considered to be reliable. Alpha Crombach is a confidence indicator related to the measured fluctuation of the "underlying validity" of the variable. The pointer has a value of $0-1$ and is used to describe the reliability of the coefficients extracted from the questions with two possible answers or from the questions containing a scale (eg from 0 to 5). The higher the index value, the more credible the ultimate question range is. An index value of 0.7 and above is an acceptable reliability index. However, fewer boundaries may be encountered in the bibliography. The audit was performed for all parameter sets of questions where the results were used in our survey (with the exception of demographics) as shown below.

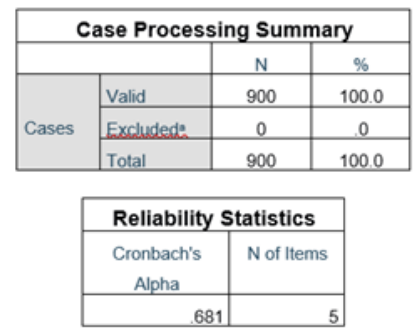

Figure 1. Reliability of statistics on questions concerning maritime training

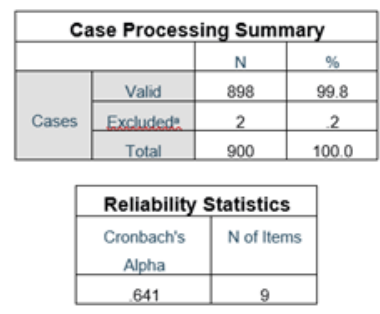

Figure 2. Reliability of statistics on questions about personality identification.

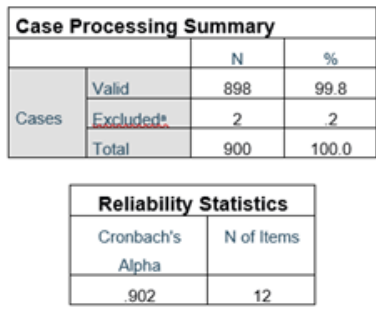

Figure 3. Reliability of statistics on questions about the workplace.
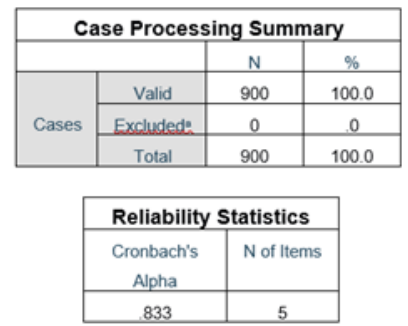

Figure 4. Reliability of statistics on questions abouthow to deal with living problems.
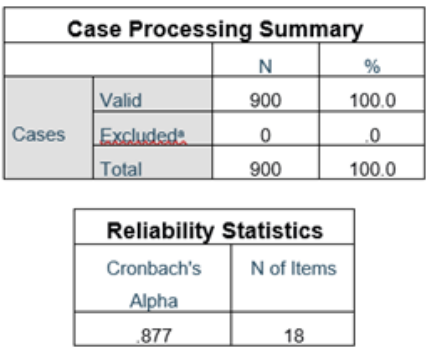

Figure 5. Reliability of statistics on questions aboutpersonal well-being during the last trip.

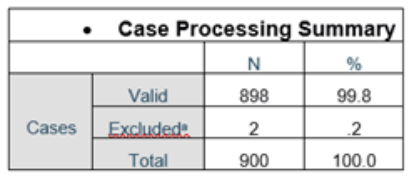

\begin{tabular}{|c|c|}
\hline \multicolumn{2}{|c|}{ Reliability Statistics } \\
\hline $\begin{array}{c}\text { Cronbach's } \\
\text { Alpha }\end{array}$ & N of ltems \\
\hline 753 & 41 \\
\hline
\end{tabular}

Figure 6. Reliability of statistics on questions about

working conditions.

As far as validity is concerned, the questionnaire was evaluated by maritime and human factor experts as satisfactory with respect to the research objectives.

\section{RESEARCH PROCESS}

With the relevant written permission from the competent Ministry of Merchant Marine and Island Policy, questionnaires distributed to the Maritime Training Center of the Merchant Marine Corps (KESEN) - the period 15-22 May 2017. The questionnaires were distributed to both the Masters and Engineering students. 282 questionnaires were collected and registered and then a first statistical processing was carried out. The survey continued with questionnaire sharing from 1 September 2017 to 20 June 2018, where 900 questionnaires were collected and more complete and reliable statistical process was made. 


\section{DATA ANALYSIS (VARIABLES, ENCODING, DATA PROCESSING FRAMEWORK)}

A variable can be measured at several scales: Scale, Ordinal (class scale), Nominal (nominal scale). If the variable is arithmetic, all three options are displayed, and if the variable is a string, we only have the Nominal and Ordinal options.

Nominal is used only for virtually all qualitative variables, those that are not measurable but only enumerated.

Class scale, Ordinary scale, looks like nominative, but it has the extra feature that records are classified into categories that follow a series of physical or logical additions, ascending or descending.

The Scale has the same properties as the Class Scale and additionally the property of predetermining equal intervals or differences between classes in any part of the scale. It is characterized by a common and constant unit of measurement. (Fachrides Georgios, 2012).

SPSS entry mode description: Free field questions were scaled in the program. The questions with distinct categories (binary type) were nominally rated and finally the five-level questions were designated as ordinal.

The statistical analysis excluded the non-answered and the multiple-answer questions as the questionnaire was not asked for.

The research questions to be evaluated are as follows:

A. Maritime education and training helps Greek seafarers to address stressful situations in their workplace?

B. The particularities and requirements of the naval profession affect the Greek Navy's psychosis?

C. Is the role of the Greek Navy in managing workplace situations?

Questions related to the above research questions and selected in this paper:

A. Maritime education and training helps Greek seafarers to address stressful situations in their workplace?

A.1. How useful do you consider to have a dedicated ship management school?

A.2. How much will you benefit from a crisis management and decision-making seminar?

A.3. Do you consider it necessary to teach a course on environmental education?

A.4. Do you consider it necessary to teach the courses using Simulator and / or other simulation programs?

B. The particularities and requirements of the naval profession affect the Greek Navy's psychosis?

B.1. Working conditions in relation to my present health.

B.2. Hours of work, round-the-clock workload, inspection, etc.

B.3. Did you have difficulty falling asleep or waking up in the evening?

B.4. Did you often feel tired, exhausted, without energy?

C. Is the role of the Greek Navy in managing workplace situations?
C.1. I think time is never enough, I have so much to do.

C.2. I am constantly in tension, difficult to relax.

C.3. Defiant work rate, pressing deadlines.

C.4. There is a lot of workload, pressure on slavery beyond my limits.

\section{RESULTS}

When hypothesis testing is performed, it is necessary to calculate X2 (statistical packet SPSS tool). The X2 independence is used to test the hypothesis that two categorical variables depend on each other.

\section{Demographics}

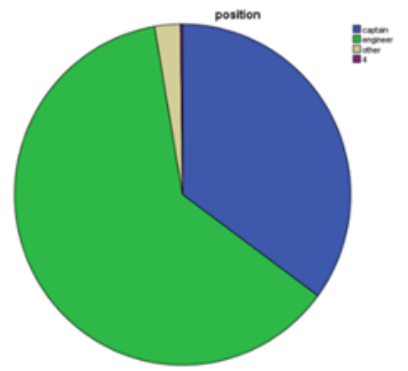

Figure 7. Sample allocation per job

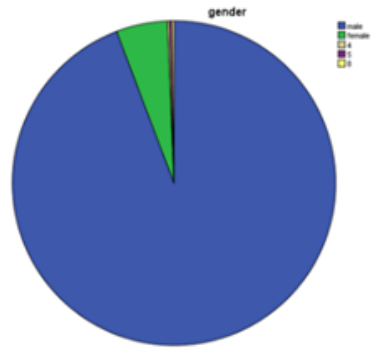

Figure 8. Sample allocation per gender

Conclusions on whether Naval Education and Training Helps Greek Mariners to Address Stressful Situations at Their Workplace

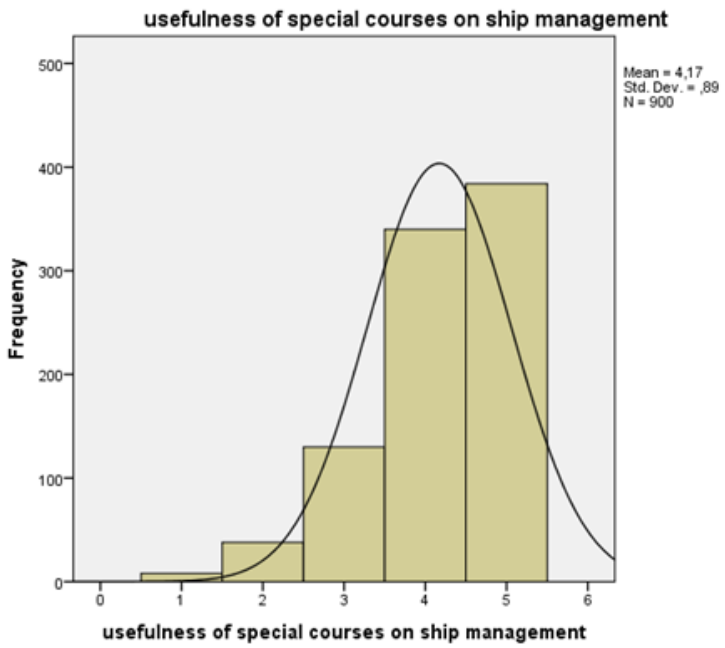

Figure 9. Results whether a special ship management school is considered to be useful. 


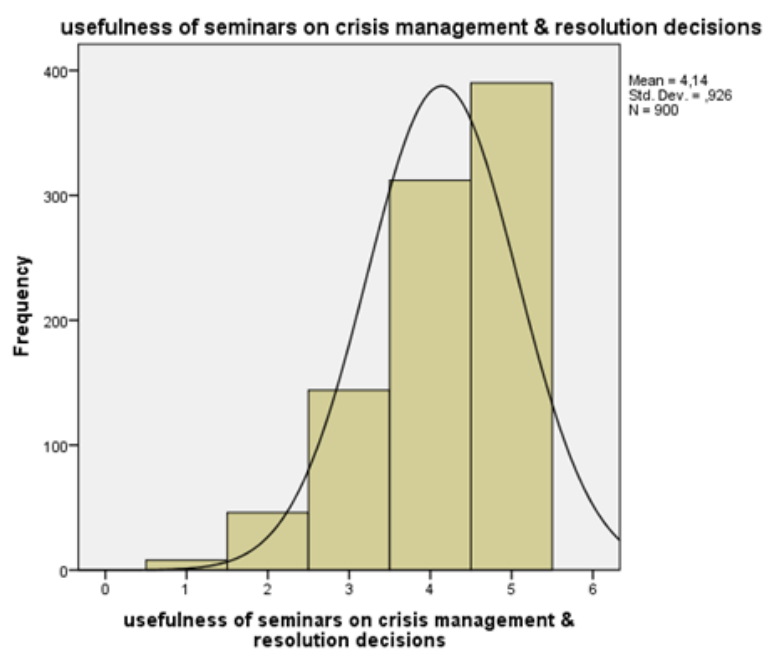

Figure 10. Results whether it will beneficial seminar on crisis management and decision-making.

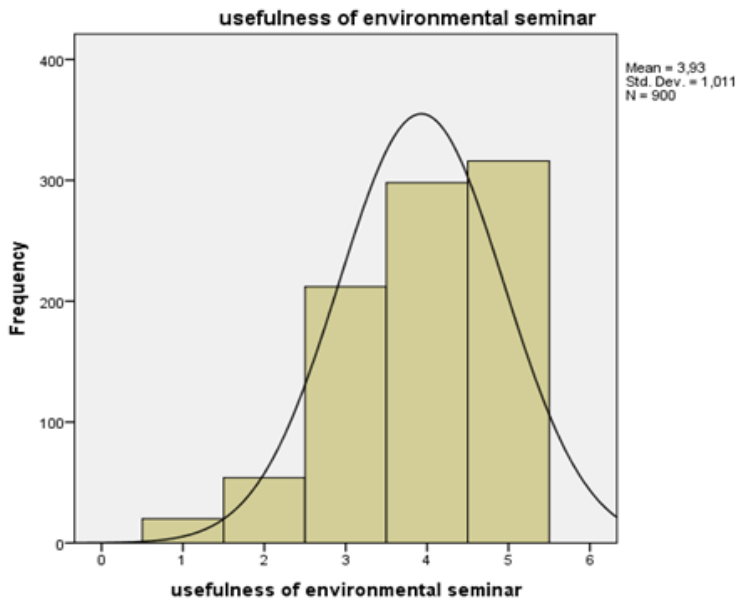

Figure 11. Results in whether it is considered necessary to teach a courseof environmental education.

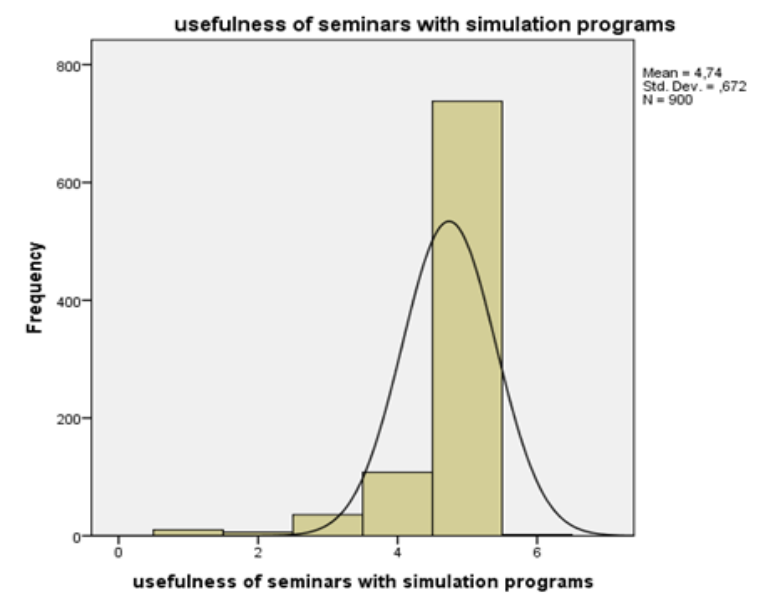

Figure 12. Results in whether it is considerednecessary to teach courses using Simulator and / or othersimulation programs.

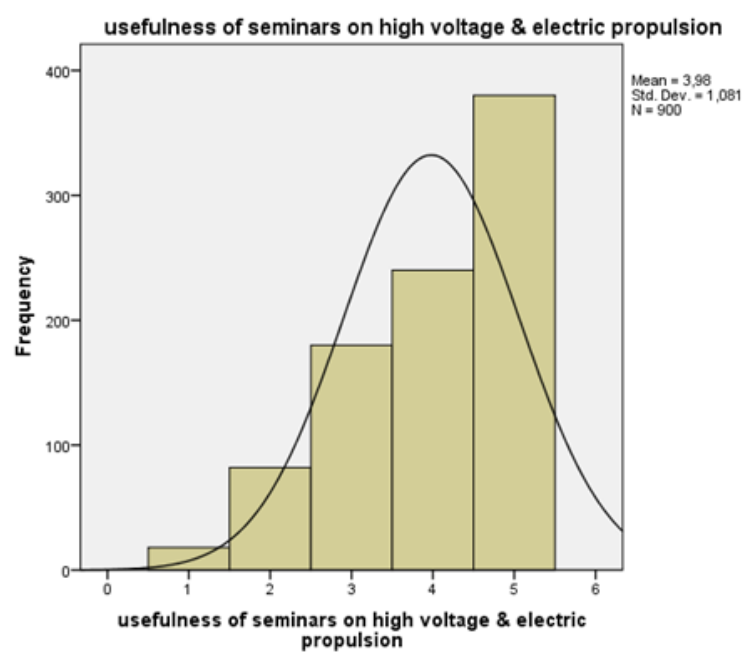

Figure 13. Results in whether it is considered necessary to teach high-voltage and electroporation courses.

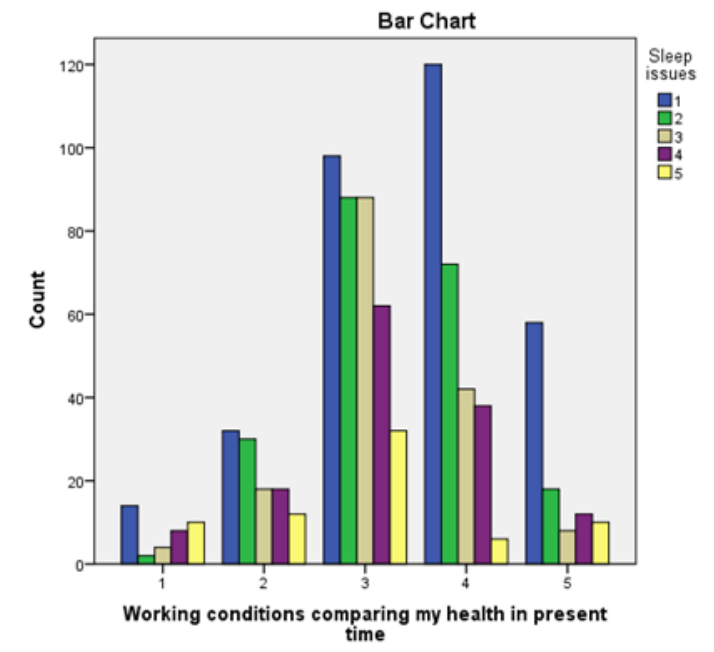

Figure 14. Results between working conditions inrelation to my present health and difficultfalling asleep or waking up at night. 


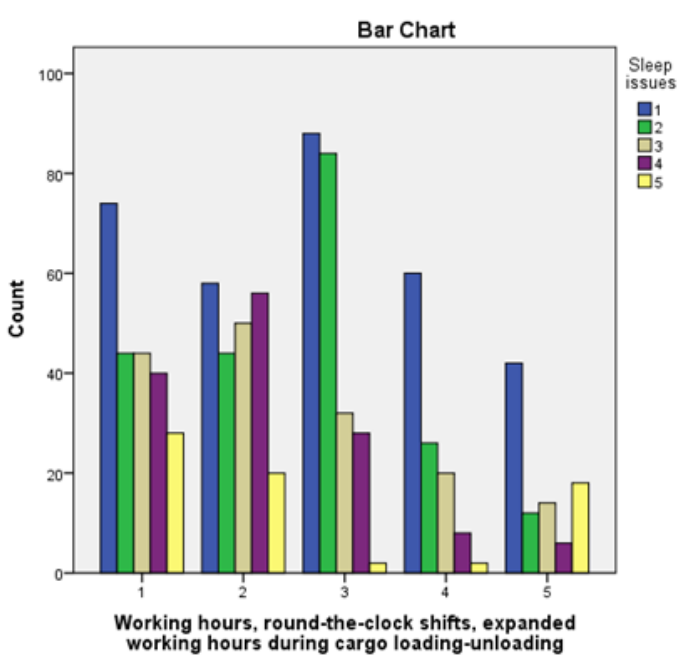

Figure 15. Results whether working hours (shift),

extended working time during unloading, inspection, etc. and if you had difficulty falling asleep or waking up in the evening.

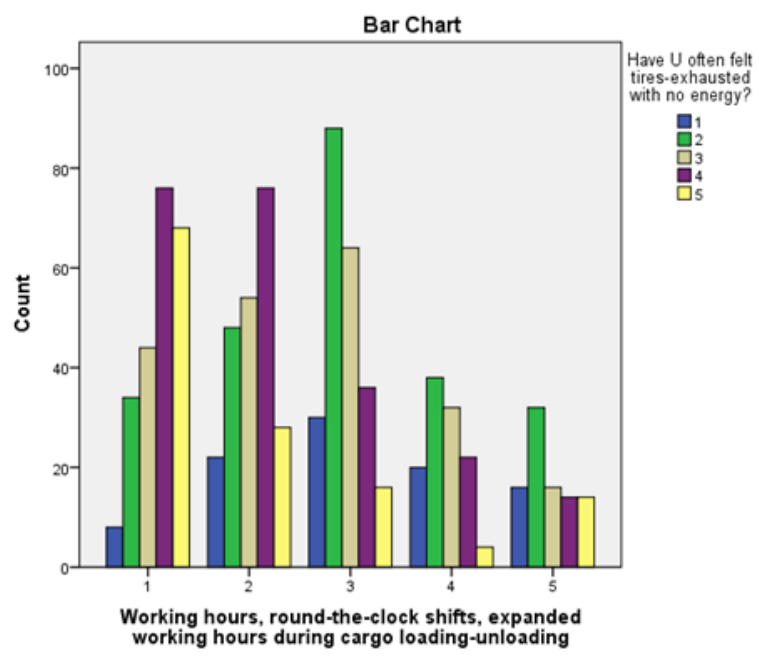

Figure 16. Results whether working hours (shift), extended working time during unloading, inspection, etc. and if you often felt tired, exhausted, without energy.

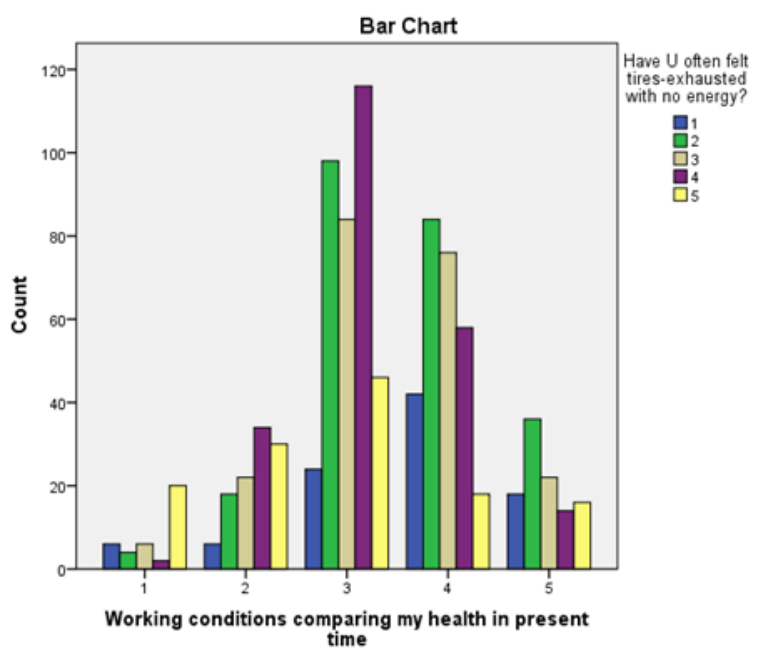

Figure 17. Results between working conditions in relation to my present health and if you often felt tired, exhausted, without energy.

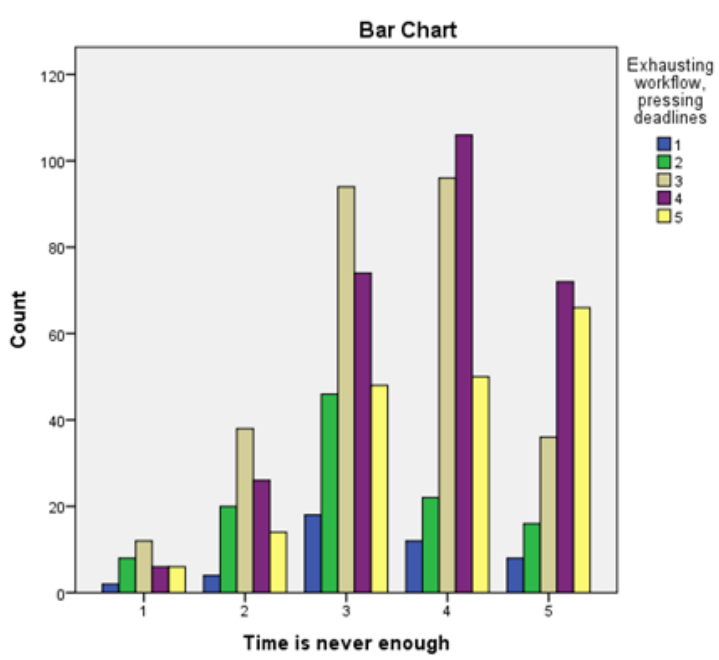

Figure 18. Results between the time that is never enough, I have so much to do and exhausting pace of work, pressing deadlines.

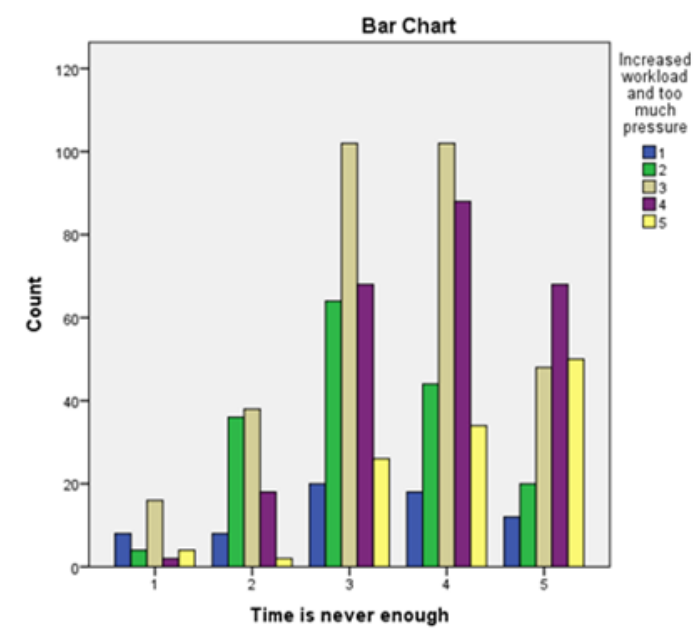

Figure 19. Results between the time that is never enough, I have so much to do and there is a lot of workload, pressure on slavery beyond my limits. 


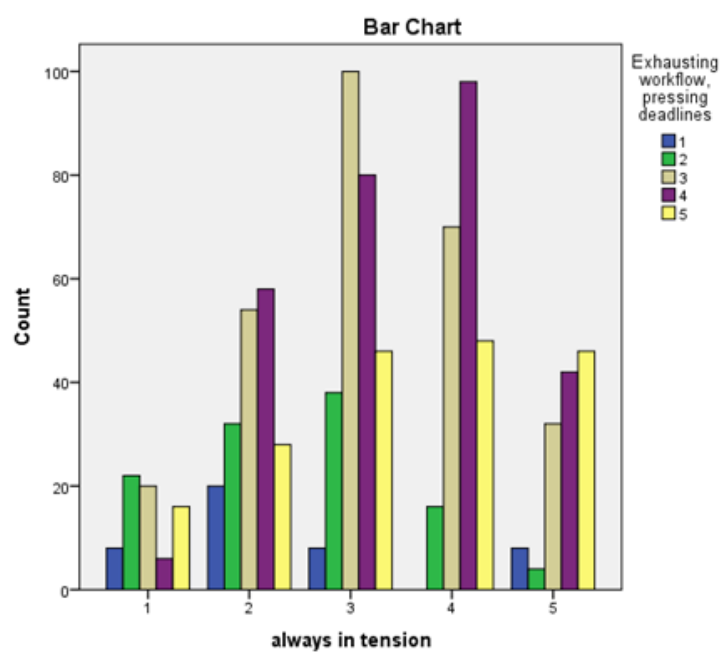

Figure 20. Results between I am constantly in tension, difficult to relax and it is a debilitating pace of work with pressing deadlines.

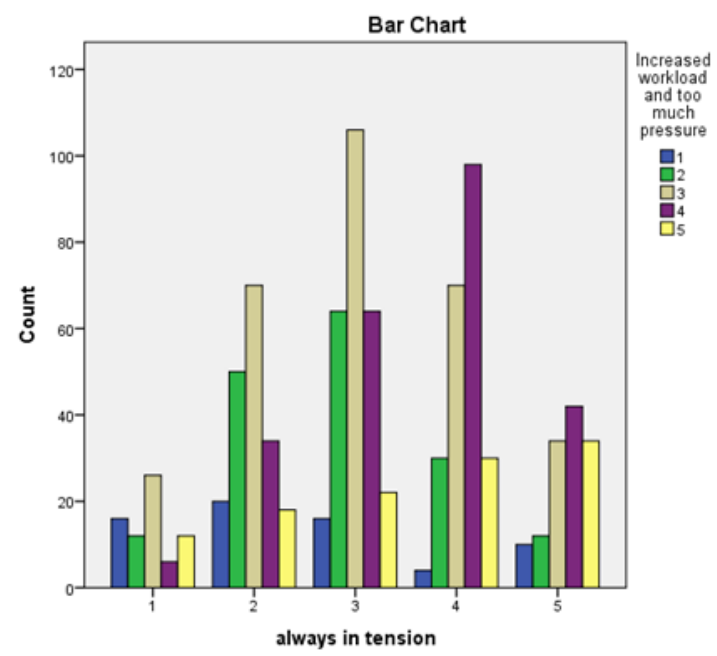

Figure 21. Results between I am constantly in tension, I hardly relax and there is a great workload, pressure on slavery beyond my limits.

\section{CONCLUSIONS}

Analyzing the factors that contribute to anxiety such as: incomplete knowledge, lack of training, absence of seminars and simulation lessons in real-world cruising conditions, increased working hours combined with the debilitating work rate and personality of the workers. Responding to the following research questions, where they were related to queries selected from the corresponding query categories.

To what extent does naval education and training helps Greek seafarers in dealing with stressful / pressures situations at their workplace?

- If the peculiarities and requirements of the naval profession affect the Greek Navy's psychosis?

\footnotetext{
- What role does the Greek Navy play in the management of workplace situations?
}

After statistical processing, it appears that all respondents answered that extra maritime education and training would be very useful. There is a correlation between the particular circumstances of the nautical profession and the mental state of the worker. It has been noticed that when the work load is overwhelming, people, especially those who are responsible, feel pressure beyond their limits. Finally, regarding health and safety necessary measures are taken. However, the average respondent claimed that recreational facilities were insufficient.

\section{FUTURE RESEARCH}

Further study (correlation of more research questions), questionnaire widening, sample expansion at Naval Academy of Sciences (AEN) students, shipping companies, sailors at sea and lower crews.

\section{ACKNOWLEDGMENTS}

All authors would like to thank the University of West Attica and specifically the Post Graduate Program of Studies (MSc) "New Technologies in Shipping and Transport", for the financial support provided to them to undertake this research project.

\section{REFERENCES}

[1] Anna-Liisa Elo, PhL. "Health and stress of seafarers."Scand J Work Environ Health 11, 1985.

[2] Essam El Sayed Ahmed Badawi, Ashraf Mohamed Halawa. The Problem of Cross Cultural and Multilingual Crews. Alexandria: 4th IAMU General Assembly, n.d.

[3] "European Agency for Safety and Health at Work." 2010.

[4] "European Survey on Working Conditions." ESWC, 2010.

[5] J.Rengamani, Dr.M.Sakthivel Murugan. "A STUDY ON THE FACTORS INFLUENCING THE SEAFARERS STRESS." AMET International Journal of Management, 2012.

[6] Manalo, Aden Raphael G., Noriel R. Mercado, Donmer F. Paragas, Justin Chris C. Tenorio, and and Jonna C. Dotimas. THE CHALLENGES OF FILIPINO SEAFARERS ONBOARD: BASIS FOR WORK LIFE BALANCE. LPU-Laguna Journal of International Tourism and Hospitality Management, 2015.

[7] MARIA JEŻEWSKA, IRENA LESZCZYŃSKA, BOGDAN JAREMIN. "WORK-RELATED STRESS AT SEA SELF ESTIMATION." Internat. Marit. Health,57, 1 - 4, 2006.

[8] Mental health of Seafarers \& Disorders. Innovative Maritime EQ Center, April 14, 2016.

[9] Swift, Dr Olivia. "Socia isolation of Seafarers." ISWAN, n.d.

[10] Welfare, International Committee on Seafarers'. "Guidelines for Mental Care Onboard Merchant Ships." SHIP@ICSW.org.uk.n.d. www.seafarershealth.org.

[11] Alexandridis, Lazarus. "Professional burnout syndrome in seafarers." AEN Macedonia Captains School, 2015.

[12] Inventory of merchant ships and crew results of September 20, 2014. Athens: HELLENIC STATISTICAL AUTHORITY, 2014.

[13] VARVOGLI, LIZA. "The Neuropsychology of Stress in Everyday Life", Kastaniotis Publishing SA , Athens 
2006.

[14] E. Thanasia, S. Kalitsari, CS Babalos, M. Delichas, A. Karageorgiou. "QUESTIONNAIRE FOR PROFESSIONAL STRESS AND PROFESSIONAL SUCCESSFUL QUESTIONNAIRE." University of Thessaly Medical School, AUTh. Department of Psychology, KEKIPK. Central Greece.

[15] K. Tripolitis, G. Triantatis. "Ch. 1, Brief reference to the working environment and the peculiarity of the naval profession. "Maritime art Emergency, 306. Publication of Academic Books, 2007.

[16] Dr. Anastasia Pantazopoulou -. Working Environment and Mental Impact. Athens: Hellenic Institute of Occupational Health and Safety, 2003.

[17] Psychosocial risks and stress at work.

[18] https://osha.europa.eu/el/themes/psychosocial-risks-andstress.

[19] Jepsen J., R., Zhao Z. and Leeuwen W., M.A, 2015. Seafarer fatigue: a review of risk factors,consequences for seafarers' health and safety and options for mitigation. Int Marit Health, 66, 2: 106-117, Via Medica.

[20] Selye H., 1956. The stress of life. New York, McGraw Hill Book Company (2nd ed, 1978)

[21] Byrne M.J., Thompson LF. Key concepts for the study and practice of nursing, 2nd ed. Saint Louis, CV Mosby
Company.

[22] Dohrenwend, B. p., Shrout, P. E., Egri, G. and Mendelson, F. S. (1980). What pshychiatric screening scales measure in the general population: II. The components of demoralization by contrast with other dimensions of psychopathology. Archives of General Psychiatry, 37.

[23] Benson, H. (Ed.). (2000). Foreword: Twenty-fifth anniversary update. In The relaxation response (pp. 145). New York: Harper Torch.

[24] Elo A. L., 1985. Health and stress of seafarers. Scandinavian Journal of Work, Environment \& Health $11,427-432$.

[25] Farber Barry A., (1983). Stress and Burnout in the Human Service Professions. New York: Pergamum Press.

[26] Moghaddum K.M. et al.(2013). Guidelines to Reducing Fatigue in Seafarers. Science explorer Publications.

[27] European Commission (2017). Seafarers: New measures to improve working conditions.

[28] Carotenuto A., Molino I., Fasanaro A., M. and Amenta F., 2012. Psychological stress in seafarers: a review. Int Marit Health 2012; 63, 4: 188-194, Via Medica

[29] Campbell, A., Converse, P., Rodgers, W. L. (1976). The quality of American life: Perceptions, evaluation and satisfactions. New York: Russell Sage Foundation. 